\title{
Human genetic markers as tracers of tumour histogenesis
}

\author{
PHILIP J. FIALKOW \\ From the Departments of Medicine and Genetics, University of Washington, Seattle, Washington, USA
}

Several questions about the origin and development of human neoplasms can be investigated by studying tumours which arise in subjects who have two or more genetically distinct types of cells. For example, if two cell types are present in normal tissues, but the tumour contains only one type, clonal origin is suggested. Similarly, the detection of both cell types in a neoplasm suggests multicellular origin. Selected studies of tumours from human females whose cellular mosaicism is governed by $\mathrm{X}$-chromosome inactivation are reviewed in this communication. A more extensive review is published elsewhere (Fialkow, 1972).

In accordance with the inactive-X (Lyon) hypothesis, somatic cells in females have only one of their two $X$ chromosomes active. The initial choice in embryogenesis as to which $\mathrm{X}$ chromosome is to be inactive in a given cell is probably random; however, once made it is fixed not only for that cell but for all its descendants. Thus, females heterozygous at a locus on the $\mathrm{X}$ chromosome such as the one for glucose-6-phosphate dehydrogenase (G-6-PD) have two types of cell. If, for example, the subject carries a gene for the usual type of G-6-PD $\left(\mathrm{Gd}^{\mathrm{B}}\right)$ on one $\mathrm{X}$ chromosome and a common variant gene such as $\mathrm{Gd}^{\mathrm{A}}$ or $\mathrm{Gd}^{\mathrm{A}}$ - on the other, one population of cells produces $\mathrm{G}-6-\mathrm{PD}$ type $\mathrm{A}$ or $\mathrm{A}^{-}$, and the other G-6-PD type B (Davidson, Nitowsky, and Childs, 1963; DeMars and Nance, 1964). A and $A^{-}$enzymes can easily be distinguished from $B$ because they have different electrophoretic mobility. Tumours with a clonal origin in $\mathrm{Gd}^{\mathrm{B}} / \mathrm{Gd}^{\mathrm{A}}$ heterozygotes should exhibit only one type of enzyme (A or B), whereas those arising from multiple cells might have both $\mathrm{A}$ and B enzymes. The electrophoretic variants are particularly well suited for studies of mosaicism since the minor component in a mixture of $\mathrm{A}$ and $\mathrm{B}$ can be detected even if it constitutes as little as $5-10 \%$ of the total activity. $\mathrm{Gd}^{\mathrm{A}}$ and $\mathrm{Gd}^{-}$are prevalent only in black populations and approximately one third of black females are $\mathrm{Gd}^{\mathrm{B}} / \mathrm{Gd}^{\mathrm{A}}$ or $\mathrm{Gd}^{\mathrm{B}} / \mathrm{Gd}^{\mathrm{A}}$ - heterozygotes.

The first application of the G-6-PD system to the study of tumours was made by Linder and Gartler (1965a) in an investigation of heterozygotes with leiomyomas of the uterus. Normal uterine muscle adjacent to the tumours had both A and B enzyme types, but only one type was present in each tumour. Thus far single enzyme phenotypes have been reported for 184 of 185 non-necrotic tumours dissected free of the surrounding myometrium (see Fialkow, 1972). (The single exception had a relatively large amount of non-tumour tissue.)

These observations strongly suggest a single cell origin of uterine leiomyomas, but other interpretations of single enzyme phenotypes should also be considered. $\mathrm{X}$-chromosome loss and nonspecific disturbances in gene expression have been excluded for leiomyomas (Linder and Gartler, 1965a). Another possibility is that leiomyomas arise from several adjacent cells which by chance have the same G-6-PD type. If complete random cell migration occurs during the development of a tissue, the chance that two contiguous cells will be alike is $0 \cdot 5$. This probability rises with increasing degrees of coherent clonal growth, since the daughter cells remain adjacent to one another and form patches of cells which have the same enzyme type. The size of the patches can be estimated for a given tissue from the degree of heterogeneity in mosaic composition of multiple small tissue samples. The estimates are based on the fact that the degree of heterogeneity in A:B composition between samples is inversely related to the number of patches per sample. A patch size of 10000 cells has been estimated for normal uterine myometrium (Linder and Gartler, 1965b). Assuming this patch size or even one larger by an order of magnitude, the probability that all 184 leiomyomas with a single enzyme phenotype arose from two adjacent cells which by chance had the same G-6-PD type is less than 0.001. The probability for origin from more than two cells is still lower.

Another possibility is that in a tumour initially composed of both A and B cells, one type enjoys a proliferative advantage; the ultimate result is a 
tumour with a single enzyme phenotype despite its multicellular origin. Selection may be dependent upon G-6-PD phenotype or upon phenotypic differences determined by other X-linked loci. The ratio of $A$ to $B$ tumours in the 184 leiomyomas is close to $1: 1$ indicating that selection on the basis of G-6-PD phenotype alone is not a major factor in tumourigenesis. Furthermore, all but one of 17 subjects from whom more than three tumours were studied had some type A and some type B tumours. This fact not only indicates that each tumour arose independently and not by some metastatic process, but it also makes unlikely the possibility that single enzyme phenotypes in leiomyomas are due predominantly to a selective advantage governed by the G-6-PD locus or a locus linked to it. If that were the case, multiple tumours from the same patient should all have the same G-6-PD phenotype.

We have applied a similar experimental approach to the study of chronic myelocytic leukaemia. The first question we explored is, Does chronic myelocytic leukaemia have a clonal origin? Since this disease involves blood cells, cultured skin fibroblasts derived from females with the disease were studied to determine whether the subjects were G-6-PD heterozygotes. In our initial investigation, three $\mathrm{Gd}^{\mathrm{B}} / \mathrm{Gd}^{\mathrm{A}}$ females with chronic myelocytic leukaemia were ascertained (Fialkow, Gartler, and Yoshida, 1967). One of these patients was from Mozambique and the other two from the United States. Although both A and B enzyme types were present in skin fibroblasts, preparations derived from millions of chronic myelocytic leukaemia blood granulocytes contained only a single enzyme type.

In contrast to the findings in chronic myelocytic leukaemia, 34 subjects without leukaemia who had both $A$ and $B$ enzymes in skin always displayed double enzyme phenotypes in blood granulocytes (Fialkow, 1973). Therefore, the single enzyme phenotypes in chronic myelocytic leukaemia must be related to the disease and most likely reflect a clonal origin for the condition. Leukaemia cells from the first three patients studied showed only type A enzyme (Fialkow et al, 1967), but in a subsequently studied patient, the single enzyme phenotype in the chronic myelocytic leukaemia granulocytes was B (Barr and Fialkow, 1973).

Earlier studies utilizing another kind of marker, the Philadelphia ${ }^{1}\left(\mathrm{Ph}^{1}\right)$ chromosome also suggested a clonal origin for chronic myelocytic leukaemia (Nowell and Hungerford, 1960). This abnormal chromosome number 22 , which lacks about $40 \%$ of its DNA, occurs almost exclusively in chronic myelocytic leukaemia. When present, it is generally found in most dividing marrow cells (Sandberg, Ishihara, Crosswhite, and Hauschka, 1962; Tough,
Jacobs, Court Brown, Baikie, and Williamson, 1963; Whang, Frei, Tjio, Carbone, and Brecher, 1963). Although these observations suggested a single cell origin, before the studies with G-6-PD one could not exclude the possibility that the abnormal leukocytes were derived from many parent cells as might occur if, for example, some aetiological agent had affinity for a specific region of DNA on the involved chromosome number 22. In this case $\mathrm{Ph}^{1}$ chromosome could arise independently in many cells. The evidence derived from studies of G-6-PD makes it appear much more likely that the abnormal cells in clinically evident chronic myelocytic leukaemia have a clonal origin.

Tough and associates (1961) reported one patient who may have had two abnormal clones. This man had features of Klinefelter's syndrome, a disorder usually associated with an extra chromosome $(47, X X Y)$. Only cells of this type were found in the skin, but mosaicism of these cells and normal cells was observed in blood and marrow (Lawler and Sanger, 1970). Since a proportion of each cell type lacked the $\mathrm{Ph}^{1}$ chromosome, the patient probably had $46, X Y / 47, X X Y$ mosaicism before the development of chronic myelocytic leukaemia. Both lines also had cells with the $\mathbf{P h}^{1}$ chromosome, which could therefore have arisen in two separate stem cells (a $47, \mathrm{XXY}$ and a $46, \mathrm{XY}$ cell). Alternatively, as the authors noted, the $\mathrm{Ph}^{1}$ chromosome could have arisen in a stem cell for only one line (eg, 47,XXY) which subsequently underwent a further divisional error to give rise to the other $\mathbf{P h}^{\mathbf{1}}$-positive cell line. In a subsequently reported patient with chromosome mosaicism and chronic myelocytic leukaemia, the data were most consistent with origin of the $\mathbf{P h}^{1}$ chromosome in a single cell (Fitzgerald, Pickering, and Eiby, 1971).

The second question we explored in the study of chronic myelocytic leukaemia is, In which type of cell does the disorder arise? Like the chronic myelocytic leukaemia granulocytes, red blood cells in the three $\mathrm{Gd}^{\mathrm{B}} / \mathrm{Gd}^{\mathrm{A}}$ heterozygotes contained only a single enzyme type (type A) (Fialkow et al, 1967). By contrast, both $A$ and $B$ enzymes are found in the erythrocytes of nearly all normal $\mathrm{Gd}^{\mathrm{B}} / \mathrm{Gd}^{\mathrm{A}}$ heterozygotes. These observations indicate that the chronic myelocytic leukaemia clone arises in a stem cell common to the erythrocyte and granulocyte but not to the skin fibroblast. This explanation is supported by the demonstration of the $\mathbf{P h}^{1}$ chromosome in erythrocyte precursor cells (Clien and Flemans, 1966; Rastrick, Fitzgerald, and Gunz, 1968).

Thus, G-6-PD and $\mathrm{Ph}^{\mathbf{1}}$ chromosome studies indicate that the alteration responsible for chronic myelocytic leukaemia occurs in a myeloid stem cell. However, cytologically this disease is not considered 
to be a stem cell leukaemia. The predominant picture in the marrow is an overabundance of myelocytes and more mature granulocytic cells. To reconcile these cytological observations with the genetic data, it seems necessary to postulate that the normal stem cell population is replaced by chronic myelocytic leukaemia stem cells, which in turn give rise to the overabundant myelocytic cells.

The third question we explored is, Does the abnormal clone persist during remission or do normal cells repopulate the marrow? Two of the $\mathrm{Gd}^{\mathrm{B}} / \mathrm{Gd}^{\mathrm{A}}$ heterozygotes with chronic myelocytic leukaemia had chemotherapeutically induced remissions during which the single enzyme type persisted in peripheral blood cells (Fialkow et al, 1967). This finding and the fact that the percentage of marrow cells with the $\mathrm{Ph}^{1}$ chromosome does not decline during remission provide clear evidence that the abnormal clone persists during remission.

Another malignancy which we have studied extensively is Burkitt lymphoma. This lymphoblastoid neoplasm with a presumable viral aetiology occurs with notable frequency in young children in Africa and certain areas of New Guinea. Thirty-two of 33 tumours from 19 G-6-PD heterozygotes studied on initial presentation had single enzyme phenotypes despite the fact that normal tissues (including lymph nodes and blood lymphocytes) always had both A and B types of G-6-PD. Tumours from 11 heterozygotes were typed as $B$, from seven as $\mathbf{A}$, and from one patient as AB (Fialkow, Klein, Gartler, and Clifford, 1970; Fialkow, Klein, Clifford, and Singh, 1973). It seems likely that at least the great majority of individual Burkitt tumours have a clonal origin. The one double enzyme phenotype tumour may have been composed of two or more clones.

Seven heterozygotes had two Burkitt tumours which could be studied and in all instances both tumours had the same single enzyme type (Fialkow et al, 1970; Fialkow et al, 1973). The probability that this occurred by chance alone is less than $1 \%$, and it seems likely that the entire disease has a single cell origin, ie, it begins at one place in a single cell and then spreads to other parts of the body. Results of studies using another cell marker, surfaceassociated immunoglobulin, are in accord with this view (Fialkow et al, 1973). Thus, if Burkitt lymphoma is caused by a virus, only a single cell may be transformed. Alternatively, the virus may be but one of several factors necessary for tumourigenesis and one of the other factors affects only a single cell. A related possibility is that many cells are altered by the virus; but once a malignant clone emerges, the growth of other clones is inhibited, perhaps by a process akin to concomitant immunity.
Another question explored in the Burkitt lymphoma study is, What is the nature of a Burkitt recurrence? Is this reemergence of the original malignant cell line or perhaps a new malignant clone developing in a susceptible patient? Thus far, only one recurrent tumour arising at a site far removed from the original site of a neoplasm after a relatively long remission has been studied in a G-6PD heterozygote (Fialkow, Klein, and Clifford, 1972a). Before therapy the patient's ovarian neoplasm was typed as B. Three months after institution of therapy she was judged to be in total remission but one month later disease recurred in the left parotid. That tumour was also typed as B. Ten weeks later a tumour was noted in the left orbit for the first time, and, unlike the first two neoplasms, it had an $A$ phenotype. This observation strongly suggests that late exacerbations of disease after total tumour regression may be due to new occurrence of disease rather than to reemergence of the original malignant cell lines. Results obtained using cell surface-associated IgM as a marker support this suggestion (Fialkow et al, 1973).

Study of carcinomas is difficult because the tumour tissue is generally contaminated with non-neoplastic constituents such as blood cells, stroma, and normal tissue. When account is taken of this, data in carcinoma of the postnasal space and other sites in the head and neck are compatible with clonal origins for these malignancies (Fialkow, Martin, Klein, Clifford, and Singh, 1972b). However, it seems likely that at least one carcinoma of the colon (Beutler, Collins, and Irwin, 1967) and perhaps some cases of carcinoma of the cervix have multicellular origins (Smith, Townsend, and Sparkes, 1971a; but see also Park and Jones, 1968).

Under what circumstances might one expect tumours to arise from multiple cells? This type or origin implies that a relatively large number of cells is innately susceptible and/or that the external aetiological agent is one that affects many cells simultaneously. For example, a multicellular origin could be found for tumours caused by viral transformation of multiple adjacent cells. The data suggest that this is not the case in Burkitt lymphoma, the malignancy in man for which there is the most evidence, albeit indirect, of a viral aetiology. Furthermore, study of the one human neoplasm with a proven viral cause, Verruca vulgaris (the common wart), suggests a clonal origin (Murray, Hobbs, and Payne, 1971). Only one type of G-6-PD was found in single warts from $6 \mathrm{Gd}^{\mathrm{B}} / \mathrm{G}^{\mathrm{A}}$ heterozygotes. These data imply that the development of a mature wart does not depend upon viral spread from cell to cell and that a clonal origin is likely.

Hormones could also bring about the develop- 
ment of tumours from more than a single cell since presumably a whole organ would be exposed to the oncogenic environment. Thyroid adenomas from five patients (Linder, 1969; Fialkow et al, 1972b) and thyroid carcinomas from two patients (Fialkow et $a l, 1972 b)$ had single enzyme phenotypes. One hypothesis to explain the development of thyroid adenomas is that these lesions are not true tumours, but rather endocrine-influenced alterations in growth patterns. The fact that thyroid adenomas have single enzyme phenotypes and presumably clonal origins makes this hypothesis unlikely. Of possible relevance is the fact that all of the three reported carcinomas of the breast have double enzyme phenotypes compatible with multiple cell origins (McCurdy, 1968; Smith, Townsend, and Sparkes, 1971b). Information about other endocrineinfluenced tumours and about more cases of breast carcinoma with careful histological examination to evaluate the possibility of contamination with nonneoplastic cells would be of considerable interest.

The origin might also be multicellular if the target tissue for the oncogenic factors contained a large number of susceptible cells. Tumours which arise in individuals with simply inherited syndromes such as multiple neurofibromatosis might have a multicellular origin because all target cells have the inherited tumourigenic potential. Double enzyme phenotypes were observed in each of 14 neurofibromas from two G-6-PD heterozygotes with multiple neurofibromatosis (Fialkow, Sagebiel, Gartler, and Rimoin, 1971). Careful histological study excluded significant contamination by nontumour cells, and, as there was no evidence for activity of both $\mathrm{X}$ chromosomes in single cells, the double enzyme phenotypes almost certainly indicate a multiple cell origin of neurofibromas in this hereditary syndrome. Similar findings have been reported for another inherited tumour, multiple trichoepithelioma (Gartler, Ziprkowski, Krakowski, Ezra, Szeinberg, and Adam, 1966).

\section{Summary}

The G-6-PD marker system has been successfully employed to investigate the development of several tumours. However, the aetiologies of most studied human tumours are unknown. If X-linked genetic marker studies could be done in tumours with known aetiology, the results might have implications for neoplasms of unknown cause. This approach is currently limited by the small number of human neoplasms for which an aetiological agent has been defined, and by inability to detect markers at the cellular level for X-linked loci with frequently occurring variant alleles other than G-6-PD. Until more markers are discovered, continued investigation of human tumours with X-linked markers is essentially confined to black populations. In addition to further studies of hereditary tumours, warts, and Burkitt lymphoma, it should be profitable to include other tumours that arise in more or less defined circumstances, such as those associated with radiation exposure, organic chemicals, and endocrine and immunological changes. Once suitable $\mathbf{X}$-linked markers are discovered in lower organisms, direct studies can be done. Hopefully, information gained from subhuman primates would have a bearing on the causes of human malignancies.

I wish to thank the many colleagues who collaborated with me in many of the investigations described in this communication. My studies were supported by grant no. GM 15253 from the National Institutes of Health of the US Public Health Service.

\section{References}

Beutler, E., Collins, Z., and Irwin, L. E. (1967). Value of genetic variants of glucose-6-phosphate dehydrogenase in tracing the origin of malignant tumors. New Engl. J. Med., 276, 389-391.

Barr, R. D., and Fialkow, P. J. (1973). Clonal origin of chronic myelocytic leukemia. New Engl. J. Med., 289, 307-309.

Clein, G. P., and Flemans, R. J. (1966). Involvement of the erythroid series in blastic crisis of chronic myeloid leukaemia: further evidence for the presence of Philadelphia chromosome in erythroblasts. Brit. J. Haemat., 12, 754-758.

Davidson, R. G., Nitowsky, H. M., and Childs, B. (1963). Demonstration of two populations of cells in the human female heterozygous for glucose-6-phosphate dehydrogenase variants. Proc. nat. Acad. Sci. (Wash.), 50, 481-485.

DeMars, R., and Nance, W. E. (1964). Electrophoretic variants of glucose-6-phosphate dehydrogenase and the single-active-X in cultivated human cells. In Retention of Functional Differentiation in Cultured Cells, edited by V. Defendi (Wistar Institute Symposium Monographs, no. 1), pp. 35-48. The Wistar Institute Press, Philadelphia.

Fialkow, P. J. (1972). Use of genetic markers to study cellular origin and development of tumors in human females. Advanc. Cancer Res., 15, 191-226.

Fialkow, P. J. (1973). Primordial cell pool size and lineage relationships of five human cell types. Ann. hum. Genet., 37, 39-48.

Fialkow, P. J., Gartler, S. M., and Yoshida, A. (1967). Clonal origin of chronic myelocytic leukemia in man. Proc. nat. Acad. Sci. (Wash.), 58, 1468-1471.

Fialkow, P. J., Klein, G., and Clifford, P. (1972a). Second malignant clone underlying a Burkitt tumour exacerbation. Lancet, 2, 629-631.

Fialkow, P. J., Klein, G., Gartler, S. M., and Clifford, P. (1970). Clonal origin for individual Burkitt tumours. Lancet, 1, 384-386.

Fialkow, P. J., Klein, E., Klein, G., Clifford, P., and Singh, S. (1973) IgM and G-6-PD as markers of cellular origin of Burkitt lymphoma. J. exp. Med., 138, 89-102.

Fialkow, P. J., Martin, G. M., Klein, G., Clifford, P., and Singh, S. (1972b). Evidence for a clonal origin of head and neck tumors. Int. J. Cancer, 9, 133-142.

Fialkow, P. J., Sagebiel, R. W., Gartler, S. M., and Rimoin, D. L. (1971). Multiple cell origin of hereditary neuofibromas. New Engl. J. of Med., 284, 298-300.

Fitzgerald, P. H., Pickering, A. F., and Eiby, J. R. (1971). Clonal origin of the Philadelphia chromosome and chronic myeloid leukaemia: evidence from a sex chromosome mosaic. Brit. $J$. Haemat., 21, 473-480.

Gartler, S. M., Ziprkowski, L., Krakowski, A., Ezra, R., Szeinberg, A., and Adam, A. (1966). Glucose-6-phosphate dehydrogenase mosaicism as a tracer in the study of hereditary multiple trichoepithelioma. Amer. J. hum. Genet., 18, 282-287. 
Lawler, S. D., and Sanger, R. (1970). Xg blood-groups and clonalorigin theory of chronic myeloid leukaemia. Lancet, 1, 584-585.

Linder, D. (1969). Gene loss in human teratomas. Proc. nat. Acad. Sci. (Wash.), 63, 699-704.

Linder, D., and Gartler, S. M. (1965a). Glucose-6-phosphate dehydrogenase mosaicism: utilization as a cell marker in the study of leiomyomas. Science, 150, 67-69.

Linder, D., and Gartler, S. M. (1965b). Distribution of glucose-6phosphate dehydrogenase electrophoretic variants in different tissues of heterozygotes. Am. J. hum. Genet., 17, 212-220.

McCurdy, P. R. (1968). Discussion of Beutler, E. The genetics of G-6-PD deficiency. In Hereditary Disorders of Erythrocyte Metabolism (City of Hope Symposium Series no. 1), edited, by E. Beutler, pp. 121-125. Grune and Stratton, New York.

Murray, R. F., Hobbs, J., and Payne, B. (1971). Possible clonal origin of common warts (Verruca vulgaris). Nature (Lond.), 232, 5152.

Nowell, P. C., and Hungerford, D. A. (1960). A minute chromosome in human chronic granulocytic leukemia. (Abstr.) Science, 132, 1497.

Park, I., and Jones, H. W., Jr. (1968). Glucose-6-phosphate dehydrogenase and the histogenesis of epidermoid carcinoma of the cervix. Amer. J. Obstet. Gynec., 102, 106-109.
Rastrick, J. M., Fitzgerald, P. H., and Gunz, F. W. (1968). Direct evidence for presence of $\mathbf{P h}^{1}$ chromosome in erythroid cells. Brit. med. J., 1, 96-98.

Sandberg, A. A., Ishihara, T., Crosswhite, L. H., and Hauschka, T. S. (1962). Comparison of chromosome constitution in chronic myelocytic leukemia and other myeloproliferative disorders. Blood, 20, 393-423.

Smith, J. W., Townsend, D. E., and Sparkes, R. S. (1971a). Genetic variants of glucose-6-phosphate dehydrogenase in the study of carcinoma of the cervix. Cancer (Philad.), 28, 529-532.

Smith, J. W. Townsend, D. E., and Sparkes, R. S. (1971b). Glucose-6phosphate dehydrogenase polymorphism: a valuable tool to study tumor origin. Clin. Genet., 2, 160-162.

Tough, I. M., Court Brown, W. M., Baikie, A. G., Buckton, K. E., Harnden, D. G., Jacobs, P. A., King, M. J., and McBride, J. A. (1961). Cytogenetic studies in chronic myeloid leukaemia and acute leukaemia associated with mongolism. Lancet, 1, 411-417.

Tough, I. M. Jacobs, P. A., Court Brown, W. M., Baikie, A., G. and Williamson, E. R. D. (1963). Cytogenetic studies on bonemarrow in chronic myeloid leukaemia. Lancet, 1, 844-846.

Whang, J., Frei, E., III, Tjio, J. H., Carbone, P. P., and Brecher, G. (1963). The distribution of the Philadelphia chromosome in patients with chronic myelogenous leukemia. Blood, 22, 664673. 